\title{
I 52 Gadolinium-labeled liposomes as a DENSE-compatible, positive MRI contrast agent for serially assessing macrophage activity and regional contractile function in the murine heart after myocardial infarction
}

\author{
Brent A French*, Alexander L Klibanov, Yaqin Xu, Elena V Galkina, \\ Ronald V Beyers, Patrick A Helm, Moriel H Vandsburger, Robert L Janiczek \\ and Frederick H Epstein
}

Address: University of Virginia, Charlottesville, VA, USA

* Corresponding author

from I th Annual SCMR Scientific Sessions

Los Angeles, CA, USA. I-3 February 2008

Published: 22 October 2008

Journal of Cardiovascular Magnetic Resonance 2008, I0(Suppl I):A53 doi:I0.I I86/I532-429X-10-SI-A53

This abstract is available from: http://jcmr-online.com/content//0/SI/A53

(C) 2008 French et al; licensee BioMed Central Ltd.

\begin{abstract}
Introduction
Monocyte/macrophage activity in the left ventricle (LV) post-myocardial infarction (MI) has previously been assessed using small/ultra-small paramagnetic iron oxide (SPIO/USPIO) particles to yield negative contrast on CMR images. However, the susceptibility-induced signal loss from iron interferes with the quantitation of myocardial strain in the very regions of interest occupied by the iron particles.
\end{abstract}

\section{Purpose}

To develop a new multimodal, multilamellar liposomal agent labeled with both Gd-DTPA (for CMR imaging) and a fluorescent tag (DiI-DS) that provides for serial macrophage tracking without interfering with cine DENSE analysis of contractile function.

\section{Methods}

Multimodal, multilamellar liposomes (MML) were prepared from 1-palmitoyl-2-oleoyl-3-sn-glycerophosphocholine and cholesterol (1:1 molar ratio), with the addition of N-methoxy-poly(ethyleneglycol)-1,2-distearoyl-3-sn-phosphoethanolamine $(<1 \mathrm{~mol} \%)$, GdDTPA-bis-stearylamide ( $7 \mathrm{~mol} \%$, Sigma Chemical) and DiI-DS (0.2 mol\%, Molecular Probes). The liposome dispersion was then passaged multiple times through $0.4 \mathrm{um}$ filters to obtain a mean diameter of $\sim 0.3 \mathrm{um}$ as determined by dynamic light scattering. Nine $\mathrm{C} 57 \mathrm{Bl} / 6$ mice were subjected to $1 \mathrm{~h}$ of coronary occlusion and up to $7 \mathrm{~d}$ of reperfusion. MML volumes of $50 \mu \mathrm{l}$ were injected IV on Day 2 post-MI for subsequent phagocytosis by monocytes/macrophages. Mice were studied by CMR $2-4 \mathrm{~h}$ after Day 2 injection and thereafter on a daily basis until Day 7 post-MI. CMR included inversion-recovery (IR) to image MML followed by IP infusion of Gd-DTPA and more IR to image the entire infarcted zone. In a subset of these studies, cine DENSE MRI [1] was performed on mid-ventricular short-axis slices prior to the IP infusion of Gd-DTPA. CMR was performed on $4.7 \mathrm{~T}$ Varian and $7 \mathrm{~T}$ Bruker/Siemens ClinScan MRI systems. Cine DENSE was performed on the ClinScan. Blood was drawn at regular intervals between $15 \mathrm{~min}$ and $6 \mathrm{~h}$ post-injection to assess DiI fluorescence by FACS and microplate reader. After the last imaging session, hearts were removed for Mac2 immunostaining, microscopy and FACS.

\section{Results}

Quantitative analysis of total DiI fluorescence revealed that $>95 \%$ of the MLLs were cleared from the blood by 4-6 $\mathrm{h}$ post injection. This notwithstanding, FACS indicated that the percentage of DiI-positive leukocytes in the blood remained fairly constant over this same period of 
time (from 50 to $75 \%$ of all CD45+ cells). CMR performed on Day 2 post-MI (2-4 h after MML injection) revealed strong Gd-enhancement in the spleen with none in the heart. In all mice from Days 3-7, strong MML enhancement marked the LV anterior wall in infarcted regions (Figure 1, Panel A). The MML contrast peaked at Day 5 and decreased by Day 7 post-MI. High-resolution, cine-DENSE imaging (Figure 1, Panel B) revealed minimal peak circumferential strain $(\mathrm{Ecc}=-0.04$ to -0.06$)$ in MMLenhanced regions as compared to normal Ecc in the remote, non-infarcted anterior and inferior septum (Ecc = -0.12 to -0.14 ). Fluorescence microscopy in 2 mice euthanized on Day 4 post-MI and in 2 mice on Day 7 post-MI showed that regions enhanced by MML on CMR (Figure 1, Panel A) corresponded well with regions containing macrophages as labeled by anti-Mac2 (Figure 1, Panel C) and DiI-DS (Figure 1, Panel D). Furthermore, FACS analysis clearly demonstrated the presence of Gr-1 $1^{\text {low }} / \mathrm{CD} 11 \mathrm{~b}+/$ CD45+/DiI-DS-positive macrophages in infarcted hearts on Day 7.

\section{Conclusion}

Multimodal, Multilamellar Liposomes are useful for assessing monocytes/macrophage infiltration into the infarcted LV where they remain detectable until at least Day 7 post-MI. The integral Gd-DTPA tag provides for highly-
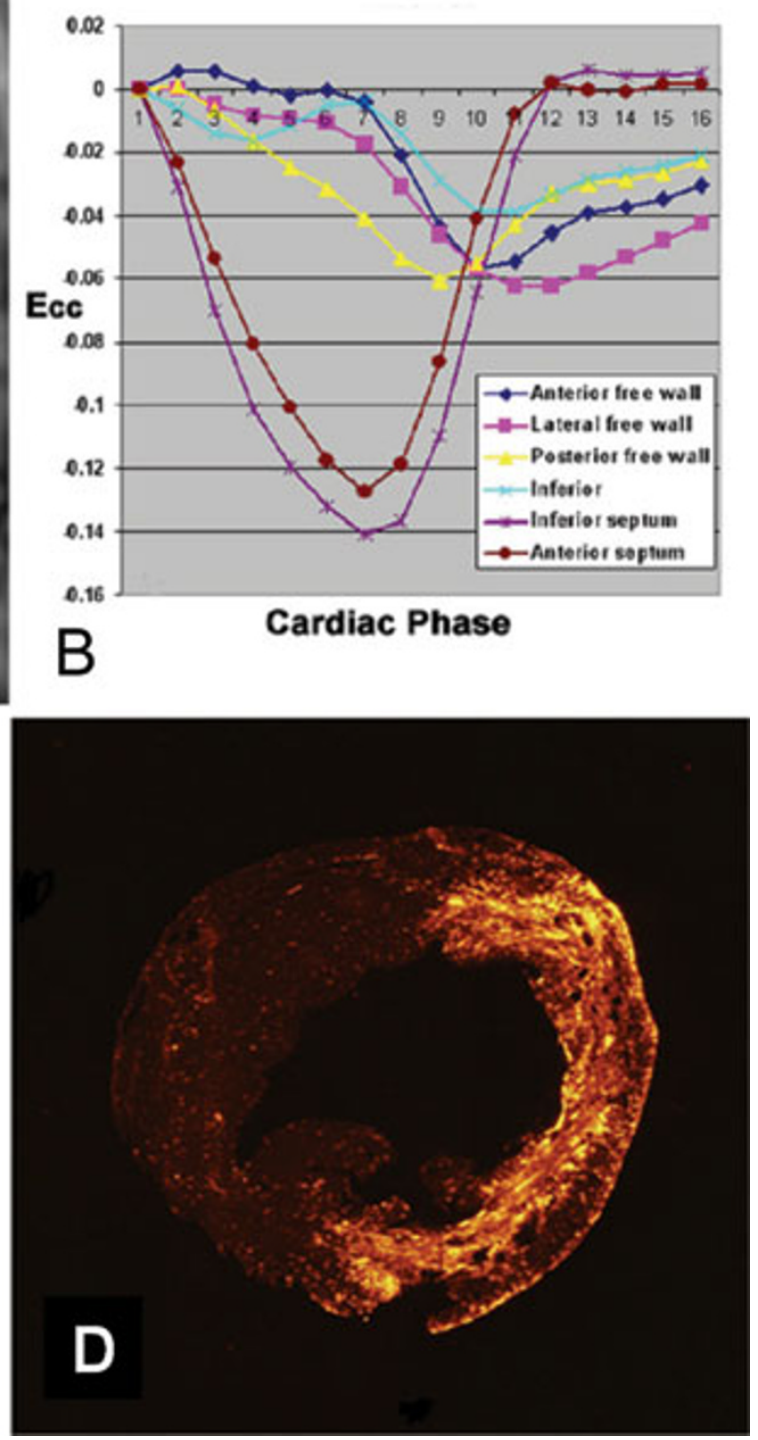

\section{Figure I}

A new multimodal, multilamellar liposomal contrast agent labeled with both Gd-DTPA and a fluorescent tag is described that provides for serial macrophage tracking after myocardial infarction and, unlike iron-based agents, is compatible with cine DENSE analysis of regional contractile function. 
specific positive MR contrast while the fluorescent tag facilitates FACS analysis and histological confirmation via fluorescence microscopy. The MML contrast agent represents a significant advance over conventional iron-based agents, because the absence of iron enables the complementary use of myocardial strain imaging by techniques such as cine DENSE. Employed together, these methods can be used to non-invasively assess the impact of inflammatory cells on regional contractile function in vivo.

\section{References}

I. Kim, et al:: Radiology 2004, 230:862-87I.

Publish with Biomed Central and every scientist can read your work free of charge

"BioMed Central will be the most significant development for disseminating the results of biomedical research in our lifetime. " Sir Paul Nurse, Cancer Research UK

Your research papers will be:

- available free of charge to the entire biomedical community

- peer reviewed and published immediately upon acceptance

- cited in PubMed and archived on PubMed Central

- yours - you keep the copyright

Submit your manuscript here:

http://www.biomedcentral.com/info/publishing_adv.asp 